\title{
O PROGRAMA SÃO PAULO FAZ ESCOLA E OS DESDOBRAMENTOS NA ORGANIZAÇÃO DO TRABALHO ESCOLAR NA EDUCAÇÃO DO CAMPO
}

\author{
Mariana Padovan Farah Soares ${ }^{1}$, Érika Porceli Alaniz $^{2}$
}

${ }^{1}$ Mestranda do Programa de Pós Graduação em Educação na Universidade do Oeste Paulista (UNOESTE), Presidente Prudente, SP. E-mail:
marianapfsoares@hotmail.com. Agência Financiadora - CAPES
${ }^{2}$ Doutora em Educação pela Faculdade de Educação da Universidade de São Paulo (FEUSP). Docente do mestrado em Educação na Universidade
do Oeste Paulista (UNOESTE).

\section{RESUMO}

A Proposta Curricular do Estado de São Paulo, intitulada "São Paulo Faz Escola" ocorreu no contexto das reformas educacionais de caráter neoliberal implementadas a partir de meados dos anos de 1990. A pesquisa tem como objetivo analisar a implementação do programa São Paulo Faz Escola e os desdobramentos na organização do trabalho escolar na educação do campo. Para tanto, o estudo foi realizado por meio de pesquisa bibliográfica e análise documental. Os resultados da pesquisa apontam que ao fragmentar os passos e as ações dos atores das escolas através de materiais padronizados e implantação de um currículo único para todas as escolas públicas e do campo, restringe a autonomia escolar e docente, sobretudo, desconsidera as especificidades dos sujeitos que vivem do/no campo. Concluímos que, o campo é um lugar de possibilidades e por uma educação do campo, pretende-se uma educação voltada para a vida real desses sujeitos.

Palavras-chave: Política Educacional. Programa São Paulo Faz Escola. Proposta Curricular do Estado de São. Organização do trabalho na escola. Educação do Campo.

\section{THE PROGRAM SAO PAULO DOES SCHOOL AND DEVELOPMENTS IN THE ORGANIZATION OF SCHOOL WORK IN EDUCATION OF THE FIELD}

\begin{abstract}
The Curricular Proposal of the State of São Paulo, entitled "São Paulo Faz Escola", took place in the context of neoliberal educational reforms implemented since the mid-1990s. The objective of this research is to analyze the implementation of the São Paulo Faz Escola program and The unfolding of the organization of school work in rural education. For this, the study was carried out through bibliographical research and documentary analysis. The research results point out that by fragmenting the steps and actions of school actors through standardized materials and the implementation of a single curriculum for all public and rural schools, it restricts school and teacher autonomy, above all, disregards the specificities of the subjects Who live from / in the field. We conclude that, the field is a place of possibilities and an education of the field, it is intended an education directed to the real life of these subjects.

Keywords: Educational politics. São Paulo School Program. Curricular Proposal of the State of São. Organization of work in school. Field Education.
\end{abstract}

\section{INTRODUÇÃO}

As reformas educacionais implementadas a partir de meados dos anos de 1990, alinhadas aos pressupostos neoliberais, tiveram como consequência, dentre vários aspectos, a implementação da Proposta Curricular do Estado de São Paulo, intitulado programa "São Paulo Faz Escola". O referido programa faz parte de um arranjo de medidas adotadas para a educação básica que altera o cotidiano das escolas públicas a partir de 2008, sendo esta uma realidade presente também nas escolas do campo no Estado de São Paulo.

Os princípios norteadores da proposta educacional têm como objetivo homogeneizar o currículo e a prática escolar, de modo que, o currículo é concebido como um produto acabado para as mais de cinco mil escolas públicas de toda a rede estadual, inclusive para as escolas do campo. 
Cabe salientar que a Educação do Campo, a princípio, contrapõe-se a concepção da Educação advinda das escolas oficiais estaduais, uma vez que está relacionada ao contexto, trajetória de luta, modo de vida e de produção do campo, havendo especificidades diferentes que precisam ser respeitadas. Como bem enfatiza Vendramini (p.129, 2007),

A defesa de uma educação

do campo tem como sustentação $\quad 0$ reconhecimento de uma realidade de trabalhadores e trabalhadoras que têm resistido para continuar produzindo sua vida no espaço rural. $\mathrm{E}$, especialmente, $\quad 0$ reconhecimento de que esta realidade precisa ser alterada, tendo em vista a crescente pobreza, o desemprego, as grandes desigualdades sociais e as dificuldades de acesso às políticas públicas (saúde, educação, transporte, infraestrutura etc.). Portanto, pensar um projeto de educação do campo pressupõe a sua sustentabilidade em termos econômicos, sociais e culturais.

Não obstante, por uma educação do campo há a defesa da especificidade de lutas e práticas que ela concebe, buscando trabalhar com a riqueza social e diversidade humana dos sujeitos que vivem do e no campo.

Sendo assim, o estudo tem como objetivo identificar e analisar a implementação do Programa São Paulo Faz Escola e os desdobramentos na organização do trabalho escolar na educação do campo.

\section{METODOLOGIA}

Para a realização desta pesquisa foi utilizado como metodologia a pesquisa bibliográfica e análise documental acerca da temática em estudo. Lüdke e André (1986, p. 11) apontam que,

das metodologias
qualitativas. Apesar da
$\begin{aligned} & \text { crescente popularidade } \\ & \text { dessas metodologias, }\end{aligned}$
ainda parecem existir
muitas dúvidas sobre o
que realmente caracteriza
uma pesquisa qualitativa,
quando é ou não
adequado utilizá-la.

Assim, foram selecionados estudos com base em artigos, artigos e dissertações que respondiam a temática desta pesquisa. Este tipo de pesquisa fornece ao pesquisador um repertório grande de estudos publicados na área que podem dar subsídios para encontrar diversas possibilidades de atuação, bem como refletir sobre possíveis intervenções.

A análise documental envolveu o levantamento e a seleção de documentos da implantação da Proposta do Programa São Paulo Faz Escola, materiais padronizados destinados às escolas e as portarias que definem as orientações sobre a nova proposta e os passos que direcionam os professores a seguirem em sua prática docente. Gil (1999) aponta que a análise documental relaciona-se muito com a pesquisa bibliográfica, na qual sua diferença se baseia na natureza das fontes. Enquanto a pesquisa bibliográfica traz contribuições de diversos autores sobre determinadas temáticas, a pesquisa documental possibilita que o pesquisador possa recorrer a materiais, exploração de fontes documentais que não receberam uma análise aprofundada ou que ainda podem ser reelaborados conforme os objetivos propostos do estudo.

\section{RESULTADOS}

A estruturação da Proposta Curricular ao determinar todo o conteúdo, tempo, rotina, metodologia e avaliação a serem seguidos pelo professor, acaba por "engessá-lo", limitando sua autonomia e retirando o próprio sentido do seu trabalho como construtor do conhecimento. Nas palavras de Cação (2011, p.16):

Aprofunda-se
experiência alienada do
trabalho docente: o
currículo e o seu
planejamento não mais
lhes pertencem. As
formas de organização do


trabalho apresentam-se estranhas a docentes e gestores. As relações e condições de trabalho depauperam-se.

Intensifica-se a

exploração, a alienação. 0 trabalho alienado impede ao professor identificarse como classe social com interesses antagônicos aos da burguesia.

Num contexto de materiais didáticos padronizados, os gestores e educadores acabam se desvinculando de seu importante papel de idealizadores do seu próprio trabalho e passam a serem executores de algo já pronto, determinado externamente. Num quadro da educação como produto e não como processo, os professores, particularmente, são visivelmente privados do seu incontestável papel de construtores da prática docente e curricular.

A padronização com o uso
de material estruturado
para toda a rede retira da
escola essa autonomia de
elaborar seu projeto
político-pedagógico, ao
centralizar para atores
externos à escola as
decisões sobre o currículo,
retirando o envolvimento
dos profissionais, da
comunidader local e
escolar no processo
educativo, os quais
tornam apenas
executores. (SILVEIRA;
MIZUKI, 2011, p.87).

Desse modo, ao introduzir uma padronização da organização curricular e do trabalho desenvolvido nas escolas se ignora as características e especificidades de cada unidade escolar, sobretudo, os anseios e expectativas dos seus profissionais e usuário em relação à educação, comprometendo significativamente a organização de um trabalho escolar real e autônomo.

É oportuno enfatizar que, tal padronização vai contra os princípios estabelecidos na Constituição Federal (1988) e contra a Lei de Diretrizes e Bases (1996).

A Constituição Federal de 1988 (CF) e a Lei de Diretrizes e Bases da
Educação Nacional de 1996 (LDB) estabelecem, como um dos princípios pelos quais $o$ ensino deverá ser ministrado, a "pluralidade de concepções pedagógicas" (CF, art. 206, inciso III; LDB, art. 3으, inciso III). Segundo Azanha (1998, p.19), a "relevância desse princípio está justamente no fato de que ele é a tradução no nível escolar do próprio fundamento da convivência democrática que é a aceitação das diferenças". (SILVEIRA; MIZUKI, 2011, p. 83).

No entanto, por uma educação voltada para o desenvolvimento, ao interesse sociocultural e econômico dos trabalhadores que vivem no/do campo, pretende-se uma educação capaz de identificar e reconhecer a realidade do sujeito a partir de saberes, conhecimentos, experiências e cultura advinda do meio em que vivem.

\section{DISCUSSÃO}

Criado em 2007 e implementado em 2008, o Programa "São Paulo Faz Escola", por meio da Proposta Curricular do Estado de São Paulo, faz parte de um arranjo de medidas adotadas para a educação básica que altera o cotidiano das escolas públicas.

Esse Programa nasceu
com a justificativa, por
parte do Estado, de que o
ensino nas escolas
públicas se apresentava
insuficiente. Para a
solução desse problema, a
solução foi criar um
material comum, pré-
elaborado, destinado a
todas as escolas da rede
(BARROS; AZEVEDO, 2016,
p.2).

De acordo com Barros e Azevedo (2016), esse material foi elaborado pela parceria com a Fundação Vanzolini, a qual contou com a colaboração de profissionais das universidades estaduais paulistas. Assim, trata-se de materiais voltados aos gestores, professores e alunos da rede estadual da educação básica. 
Assim, em 2008 também chega às escolas públicas a "Proposta Curricular" com orientações a serem acatadas pelas unidades de ensino, no entanto esta proposta se torna o novo Currículo Oficial do Estado. Em 2012, temos quatro documentos norteadores para a implantação da reforma curricular, sendo esses: a Proposta Curricular (currículo oficial), o Caderno do Gestor, o Caderno do Professor e o Caderno do Aluno. Os gestores, professores e alunos receberam apostilas que continham orientações para a prática educativa, bem como todas as atividades a serem desenvolvidas em todas as disciplinas ao longo do ano letivo.

Os professores recebem o denominado Caderno do professor, este contém atividades a serem executadas e orientações a serem seguidas pelos docentes. Os estudantes recebem um caderno de atividades, denominado Caderno do aluno, enquanto os gestores recebem o Caderno do gestor, contendo orientações sobre as medidas relacionadas ao currículo escolar, a avaliação e expectativas de aprendizagem.

O Currículo se completa com um conjunto de documentos dirigidos especialmente aos professores e aos alunos: os Cadernos do Professore do Aluno, organizados por disciplina/série(ano)/bime

stre. Neles, são apresentadas Situações de Aprendizagem para orientar o trabalho do professor no ensino dos conteúdos disciplinares específicos e a aprendizagem dos alunos. Esses conteúdos, habilidades $\mathrm{e}$ competências são organizados por série/ano e acompanhados de orientações para a gestão da aprendizagem em sala de aula e para a avaliação e a recuperação. Oferecem também sugestões de métodos e estratégias de trabalho para as aulas, experimentações, projetos coletivos, atividades extraclasses e estudos interdisciplinares. (SÃO PAULO, 2008).
Salienta-se que o caderno do professor e do aluno são elaborados de modo a definir o passo a passo de cada aula, com estratégias de ensino a serem utilizadas pelo professor, atividades e conteúdos a serem abordados, propostas de avaliação e recuperação. Diante do exposto, fica evidente que o professor se torna um mero executor de um material já pronto, ou seja, o professor é alienado de sua prática docente.

O Caderno do Professor e o Caderno do Aluno são elaborados com sequências didáticas denominadas "Situações de Aprendizagem", orientações e propostas de atividades, conteúdos e estratégias de aprendizagem que $o$ professor e o aluno devem trabalhar em sala de aula. Apresentam ainda um "passo a passo" detalhado sobre como professor deve preparar e atuar em cada aula. Os conteúdos são apresentados em forma de competências e habilidades a serem desenvolvidas e alcançadas pelos alunos também em cada aula. Ainda são apresentadas cargas horárias necessárias para o desenvolvimento de cada atividade, proposta de avaliação e de recuperação da aprendizagem (NUNES,; GARCIA, 2013, p.6).

É oportuno enfatizar que, o referido programa tem como foco a implantação de um currículo único para as mais de cinco mil escolas pública de toda a rede estadual, inclusive, para as escolas do campo, no qual todos os alunos, obrigatoriamente, devem seguir o material didático padronizado.

A justificativa apresentada pela Secretária de Educação do Estado de São Paulo (SEE/SP) para a implementação desta Proposta curricular seria a homogeneização das escolas, ou seja, que todas as escolas tenham a possibilidade de passar os mesmos conteúdos, 
ao mesmo tempo, utilizando os mesmos materiais. (SÃO PAULO, 2008).

Para tanto, a implantação do currículo oficial nas escolas do campo, realizado de forma vertical e hierárquica, desconsidera as especificidades e os anseios da realidade do campo, bem como o processo de luta que o subjaz.

A educação do campo ${ }^{1}$ advinda da luta dos Trabalhadores Rurais Sem Terra é uma estratégia para garantir inicialmente o acesso à educação, sobretudo à universalização de uma educação de classe no sentido de uma formação humana, que se opunha a postura defendida pelo estado na reprodução social do capital. Nessa perspectiva, Souza (2012, p. 759) aponta que:

A educação do campo
originou-se com o intuito
de interrogar os
condicionantes estruturais
históricos da sociedade
brasileira, entre eles a
desigualdade educacional,
os processos econômicos
e políticos excludentes e a
prática tecnocrática e
patrimonialista de
elaboração de políticas
públicas.

Conforme destaca Ribeiro (2013), o processo de luta dos Movimentos Sociais na busca por uma educação do campo tem como fundamento o Movimento Camponês e uma proposta de educação pautada na formação humana, nos saberes, nos conhecimentos e na cultura dos mesmos.

Assim, de acordo com a Constituição Federal de 1988, o artigo 205 ressalta que,

A educação é um direito
de todos e dever do
Estado e da família e será
proporcionada r e
incentivada com a
colaboração da sociedade,
na busca de pleno
desenvolvimento da
pessoa, seu preparo para
o exercício da cidadania e
de qualificação para o
trabalho (CF, 1988).

\footnotetext{
${ }^{1} \mathrm{O}$ termo referido educação do campo no presente estudo traz a perspectiva da estudiosa Caldart (2009), no qual ressalta que "do campo" traz a discussão de uma educação voltada para a vida real, vinculada as multirelações vivenciadas pelos sujeitos do campo.
}

Para Haddad (2012, p. 215) "conceber a educação como direito humano significa incluí-la entre os direitos necessários a realização da dignidade humana plena". Portanto, compreender algo como direito humano é assegurar aos seres humanos a garantia do mesmo, como por exemplo, a educação, reconhecida como direito, embora tenha sido concebida como oportunidade de poucos por muito tempo. O direito à educação implica que a sua oferta deve ser garantida para todas as pessoas, independente de sua origem, etnia, cultura e/ou religião.

Como bem ressalta Seganfredo (2014), diante do cenário de exclusão dos sujeitos do campo, a educação surge como elemento primordial para ao desenvolvimento político, econômico e sociocultural dos povos do campo, através de uma concepção educativa no qual tem seus próprios sujeitos enquanto produtores e detentores de conhecimento.

Todavia, na luta contra a desigualdade social e de um modelo hegemônico de educação, pretende-se uma educação capaz de identificar e reconhecer seus sujeitos no sentido de uma emancipação humana.

\section{CONCLUSÃO}

Em suma, o campo é um lugar possibilidades de vida dos sujeitos que vivem no/do campo, inclusive, um espaço que marcou e continua deixando sua marca na história da sociedade brasileira, a partir de todo o seu contexto de lutas e conquistas pela terra, sobretudo, por uma educação que assegurasse a esses sujeitos o direito ao trabalho e a escolarização (BAVARESCO; RAUBER, 2014).

Sendo assim, é preciso repensar os modelos educacionais, valorizando as características e especificidades, sobretudo, a diversidade do campo, para que esses sujeitos tenham a possibilidade de ter uma aprendizagem significativa. Uma educação que seja capaz de identificar e reconhecer a realidade desses sujeitos a partir de seus saberes, conhecimentos, experiências e cultura advinda do meio em que vivem. 


\begin{abstract}
são necessárias medidas diferenciadas, de norte a sul do país, que atingem especificamente as dificuldades de cada escola, sendo estas pedagógicas, de estrutura física, formação de professores, transporte escolar, entre outras, lembrando sempre das diferentes culturas e condições sociais que caracterizam 0 país (BAVARESCO; RAUBER, 2014, p. 88).
\end{abstract}

Portanto, contra a exploração e expropriação no cenário atual da sociedade brasileira, a educação do campo se opõe a posição conservadora defendida pelo estado. Por uma educação do campo voltada para a vida real dos sujeitos do campo precisamos de mais.

\section{REFERÊNCIAS}

BAVARESCO, R. P.; RAUBER, V. D. Educação do Campo: uma trajetória de Lutas e Conquistas. Unoesc \& Ciência - ACHS, Joaçaba, v. 5, n. 1, p. 85-92, jan./jun., 2014.

BARROS, R. A.; AZEVEDO, M. A. R. O impacto do Programa São Paulo faz Escola em Professores Inlciantes. Educação \& Realidade, Porto Alegre, v. 41, n. 2, p. 359-381, abr./jun., 2016. Disponível em: $\quad$ https://doi.org/10.1590/2175-623650875. Acesso em 20 mai. 2017

BRASIL. Lei no 9.394, de 20 de dezembro de 1996. Estabelece as diretrizes e bases da educação nacional. Diário Oficial da União, Brasília-DF, 23 dez. 1996. Disponível em: http://www.planalto.gov.br. Acesso em: 19 jul. 2017.

CAÇÃO, M. I. São Paulo faz Escola? Da alienação do Trabalho docente. In: ENCONTRO BRASILEIRO DE EDUCAÇÃO E MARXIMISMO; MARXIMISMO, EDUCAÇÃO E EMANCIPAÇÃO HUMANA, 5., 2011, Florianópolis. Anais ... Florianópolis: UFSC, 2011. p.1-18.

CALDART, R. S. Educação do Campo: notas para uma análise de percurso. Trabalho, Educação Saúde, Rio de Janeiro, v.7, n. 1, p. 35-64, mar-jun. 2009. Disponível em:
https://doi.org/10.1590/S1981-

77462009000100003. Acesso em: 15 abr. 2017

GIL, A. C. Métodos e técnicas de pesquisa social. São Paulo: Atlas, 1999.

HADDAD, S. P. Direito à Educação. In: CALDART, R. S. et al. (org). Dicionário da Educação do Campo. Rio de Janeiro; São Paulo: Escola Politécnica de Saúde Joaquim Venâncio, Expressão Popular, 2012.

LÜDKE, M.; ANDRÉ, M. E. D. A. Pesquisa em educação: abordagens qualitativas. São Paulo: EPU, 1986.

NUNES, P. S.; GARCIA, T. O. G. O currículo oficial na rede estadual paulista: administração gerencial e a proposta de padronização do trabalho pedagógico. Uberlândia, 2013, p. 1-14.

RIBEIRO, M. Política educacional para populações camponesas: da aparência à essência. Revista Brasileira de Educação, Rio Grande do Sul, v. 18, n. 54, jul./set., 2013.

SÃO PAULO. Secretária de Educação do Estado de São Paulo, 2008. Disponível em: $<$ http://www.educacao.sp.gov.br/>. Acesso em: 20 jul. 2017.

SEGANFREDO. K. A. Comitê Estadual da Educação do Campo: a materialização da Luta Política no âmbito da Educação do Campo no Paraná. 2014. 196f. Tese (Doutorado em Educação) Universidade Tuiuti do Paraná, Curitiba, 2014.

SILVEIRA, A.; MIZUKI, V. Sobre a legalidade da aquisição e uso dos "sistemas de ensino privados" na educação pública. Educação: Teoria e Prática, Rio Claro, v.21, n. 38, 2011.

SOUZA, M. A. Educação do Campo, Desigualdades Sociais e Educacionais. Educação \& Realidade, Campinas, v. 33 , n. 120 , p. $745-763$, jul.-set., $2012 . \quad$ Disponível em: $<$ http://www.cedes.unicamp.br $>$. Acesso em: 20 jul. 2017.

VENDRAMINI, C. R. Educação e trabalho: reflexões em torno dos movimentos sociais do campo. Cad. Cedes, Campinas, v. 27, n. 72, p. 121-135, maio/ago. Disponível em: 
http://dx.doi.org/10.1590/S0101-

32622007000200002. Acesso em: 20 jul. 2017

Recebido para publicação em: 07/08/2017

Revisado em: 15/09/2017

Aceito em: 18/09/2017 